\title{
La expresión del tabú: estudio sociolingüístico
}

\author{
Ana M. Cestero Mancera* \\ Universidad de Alcalá, España
}

\begin{abstract}
Resumen
El estudio del tabú lingüístico ha experimentado un desarrollo considerable, aunque aún limitado, en las últimas décadas, en las que se ha abordado, especialmente, desde disciplinas que trabajan con el habla, como son la sociolingüística o la pragmática, lo que ha favorecido una ampliación del objeto de estudio y la aparición de enfoques interdisciplinarios. Uno de los aspectos menos trabajados sobre la expresión lingüística de conceptos, comportamientos y realidades tabú es, no obstante, la variación condicionada por factores sociales. Por ello, con la pretensión de profundizar en el conocimiento de sus funciones discursivas y de la incidencia que tienen en su uso determinados factores sociales (sexo, edad, nivel de instrucción y clase social), estamos llevando a cabo una investigación sobre el tabú lingüístico en el habla de Madrid, que se enmarca dentro del "Proyecto para el Estudio Sociolingüístico del Español de España y América (PRESEEA)" y que enfoca el objeto de estudio desde dos ángulos diferentes: por un lado, lo que acontece en el discurso oral, en registro semiformal, y, por otro, la percepción que tenemos los hablantes sobre el empleo que hacemos de expresiones interdictas. En este trabajo, presentamos los resultados obtenidos en la primera parte
\end{abstract}

Para correspondencia, dirigirse a: Ana M. Cestero Mancera (anam.cestero@uah.es), Universidad de Alcalá, Departamento de Filología, Comunicación y Documentación, Colegio San José de Caracciolos, C/ Trinidad, 5, 28801 Alcalá de Henares (Madrid), España. 
de la investigación y las conclusiones a las que hemos llegado sobre patrones sociolingüísticos en la expresión del tabú.

Palabras clave: tabú, interdicción, sociolingüística, ortofemismo, disfemismo, eufemismo.

\title{
EXPRESSING TABOOS: A SOCIOLINGUISTIC STUDY
}

\begin{abstract}
In the last few decades the study of taboos in language has made considerable, though not yet sufficient, progress, particularly in disciplines such as sociolinguistics and pragmatics that concern themselves with the spoken word. This has led to a broadening of the object of study and to the emergence of interdisciplinary approaches. One of the more neglected aspects of the linguistic expression of taboo concepts, behaviour and realities is variation as the result of social factors. For that reason, and with a view to deepening our understanding of its discursive functions and of the repercussion on its use of certain social factors (sex, age, educational level and social class), we are carrying out research into taboos in language in the spoken language of Madrid, as part of the proyect: "Proyecto para el Estudio Sociolingüístico del Español de España y América (PRESEEA)". Our approach to the subject is twofold, considering on the one hand what happens in semi-formal oral discourse and, on the other, speakers' perceptions of the use made of taboo expressions. This article presents the results of the first part of our research and the conclusions we have reached regarding sociolinguistic patterns in the expression of taboos.
\end{abstract}

Keywords: taboo, interdiction, sociolinguistics, orthophemism, dysphemism, euphemism.

Recibido: $11 / 01 / 15 \quad$ Aceptado: $13 / 03 / 15$

\section{INTRODUCCIÓN: EL TABÚ Y EL ESTUDIO DE SU EXPRESIÓN}

El ser humano se ha sentido siempre atraído por lo prohibido, sin que ello haya impedido que lo respetara o lo transgrediera con cometidos diversos, y que quisiera conocer su origen y motivación. La prohibición de base 
cultural y social que más ha interesado a los lingüistas es la que se conoce como tabú ${ }^{1}$, entendido ya, desde principios del siglo XX, como prohibición comunicativa, un comportamiento social de reflejo directo en los actos de habla, que convierte en interdictas determinadas esferas y en innombrables o inutilizables, las unidades semánticas y léxicas que las integran.

El tabú lingüístico ha sido tratado extensamente en la bibliografía del siglo XX y de comienzos del XXI. La evolución del concepto ha ido pareja con las perspectivas disciplinarias desde las que se ha enfocado su estudio, que, de manera general, ha pasado por dos etapas claramente identificables (Martínez Valduesa 1998, Calvo Shadid 2011). La primera, que llega hasta los años setenta del siglo XX, proporcionó ideas básicas sobre el tabú, su origen y su organización en clases y subclases, en atención a las causas que lo motivan y las diversas formas de su expresión. Su reflejo en las lenguas fue tratado, fundamentalmente, por lexicólogos y lexicógrafos y semantistas, además de por algunos dialectólogos. En la segunda etapa, que llega hasta la actualidad, se produce un gran avance en el conocimiento del funcionamiento del tabú lingüístico de manos, otra vez, de lexicólogos y lexicógrafos, semantistas y dialectólogos ${ }^{2}$, pero, además, se lleva a cabo su investigación desde enfoques que, acordes a los nuevos tiempos -surgimiento de las ramas de la lingüística-, atienden, de manera fundamental, a factores externos o extralingüísticos para explicar su uso y la función que cumple, sin perder de vista las causas que lo originan, apareciendo, así, estudios profundos realizados desde la pragmática ${ }^{3}$, la sociolingüística ${ }^{4} \mathrm{o}$ la lingüística cognitiva y, recientemente, desde perspectivas multidisciplinares como son la pragmática cognitiva ${ }^{5}$ la sociolingüística cognitiva ${ }^{6}$.

1 En este trabajo, usaremos como sinónimos los términos “tabú" e "interdicción", si bien será de uso más frecuente el término "tabú", por ser el más empleado en sociolingüística.

2 Véanse los influyentes trabajos de Grimes (1978), Casas (1986, 1993) o Montero (1981 y 1995). No se puede dejar de mencionar el trabajo pionero de Kany (1960).

3 Véanse, a modo de ejemplo, los trabajos de Allan y Burridge (1991, 2006), Briz (1996 y 1998), Uría (1997), Chamizo y Sánchez (2000), Casas (2000, 2005, 2009a y 2009b), Crespo Fernández (2007, 2008), Navdal (2007) o Díaz Pérez (2012).

4 Son estudios de corte sociolingüístico los de López Morales (1990, 1997, 2001 y 2005), Vestad (1991), Hare (1995), Martínez Valdueza (1995), Danbold Drange (1997), Calvo Shadid (2008, 2013) y Fernández de Molina (2014).

5 Consideramos que los últimos trabajos de Casas Gómez (2012a y 2012b) son de corte pragmático-cognitivista; también pueden enmarcarse en esta perspectiva los estudios de Chamizo (2003, 2008 y 2009).

6 Sobre sociolingüística cognitiva como enfoque multidisciplinar véase Moreno Fernández (2012). Es destacable el excelente trabajo sobre el tabú sexual realizado por Pizarro 
Las distintas corrientes y perspectivas desde las que se ha tratado el fenómeno que nos ocupa han dado frutos diversos que resultan de gran interés y que permiten, hoy en día, unir y combinar los hallazgos obtenidos con objeto de establecer todos los factores con los que se relaciona, de manera que las investigaciones sean más abarcadoras y nos lleven a un conocimiento profundo del tema. Su estudio fue emprendido por semantistas y lexicólogos o lexicógrafos, además de algunos dialectólogos, lo que refleja la ausencia de una posición consensuada acerca de cuál es el plano implicado. Así, habitualmente, se relaciona el tabú con el léxico, pero la mayoría de los estudiosos considera que lo tabuizado en sociedad son comportamientos y realidades, conceptualizados a través del lenguaje, de manera que lo que resulta interdicto son los conceptos y, consecuentemente, los elementos léxicos que se utilizan para su expresión, lo que nos lleva a la semántica léxica. Los estudios desde esta disciplina resultan imprescindibles para conocer la forma y la función de la interdicción lingüística, así como para establecer cuáles son las esferas interdictas y qué signos lingüísticos incluye cada una, organizados por tipos.

Como hemos mencionado con anterioridad, el hecho de que existan conceptos tabú no impide que las personas hagamos referencia a ellos; sin embargo, sí implica una selección en la manera de expresarlos, que permite alejarse más o menos del significado prohibido a partir del elemento lingüístico que se elija (Pizarro 2013: 81). A este respecto, en la actualidad, se relaciona el tabú lingüístico con dos fenómenos, el eufemismo y el disfemismo, y con sus recursos lingüísticos ${ }^{7}$, además de con el ortofemismo, entendido como el uso neutro de un elemento léxico que alude a concepto o realidad interdicta (Pizarro 2013: 81). En cualquiera de los casos, nos encontramos ante la elección de un recurso u otro para aludir a un mismo concepto o realidad y, por tanto, ante un fenómeno variable; la selección que haga el emisor de una estrategia u otra podrá ser significativa (respondiendo, así, a requerimientos funcionales y pragmáticos) y estará condicionada por factores contextuales (la situación comunicativa) y sociales (las características sociales de los hablantes).

(2013) como tesis doctoral, desde la sociolingüística cognitiva; sin duda, ha creado un modelo teórico y metodológico adecuado y necesario para el estudio del tabú lingüístico.

7 Sobre eufemismos y disfemismos existe mucha y muy variada bibliografía. En el marco más próximo a nuestra investigación son destacables las caracterizaciones de Kany (1960), Montero (1981) y Casas (1986) y, con un enfoque más pragmático y pragmático-cognitivo, las de Allan y Burridge (1991 y 2006), Uría (1997), Martínez Valdueza (1998), Casas (1993, 2005, 2009a, 2012a y 2012b), Chamizo y Sánchez (2000), Chamizo (2003), Crespo (2007) y Pizarro (2013). 
El estudio de las funciones pragmático-discursivas que cumple el uso de determinadas lexías o expresiones lingüísticas que hacen referencia a realidades interdictas nos lleva al ámbito de la pragmática. En los últimos años, la clasificación funcional ha sido enriquecida por el establecimiento de finalidades con las que se usan los elementos lingüísticos que hacen referencia a realidades tabuizadas, destacadas desde un enfoque interdisciplinario de corte pragmático-cognitivo.

La investigación sobre los condicionamientos de las características sociales de los hablantes y de la situación de comunicación se ha desarrollado, en paralelo a las últimas aportaciones pragmático-discursivas, desde la sociolingüística, si bien son muy pocos todavía los estudios llevados a cabo que se enmarcan en esta disciplina, a pesar de la incidencia que tienen los factores sociales y situacionales en el tabú lingüístico y su expresión. En su mayoría, parten de las investigaciones de H. López Morales (1990, $1997,2001,2005)^{8}$ y pretenden conocer la incidencia que tienen factores sociales como el sexo, la edad o la clase social en la frecuencia de uso de determinados términos interdictos -pertenecientes, fundamentalmente, a la esfera sexual-, sin perder de vista que la variabilidad puede afectar al grado de estigmatización de conceptos y elementos ${ }^{9}$. Como último peldaño en el desarrollo de los estudios de corte sociopragmático sobre tabú y su expresión lingüística, acaba de surgir un enfoque integrador defendido y mostrado por A. Pizarro (2013). Se trata de una investigación de gran originalidad que, teniendo en cuenta los hallazgos previos sobre el tabú lingüístico, reconoce la incidencia determinante de los factores contextuales y sociales ${ }^{10}$ en su empleo y añade la implicación que tienen en su aparición algunos componentes de la personalidad, las características de los individuos y las identidades, con lo que sienta las bases teóricas y metodológicas para el estudio del tabú lingüístico desde la sociolingüística cognitiva.

8 Los trabajos iniciales de corte sociolingüístico de H. López Morales han sido replicados, con extensiones complementarias enriquecedoras, por Martínez Valdueza (1995), Danbolt Drange (1997) y Calvo Shadid (2008 y 2013). Más recientemente, Fernández de Molina (2014) ha presentado un estudio sociolingüístico utilizando el marco metodológico de estudios de la norma culta.

9 Lo que enlaza, directamente, como señala Pizarro (2013: 76), con efectos de prototipicidad y, con ello, con la lingüística cognitiva.

10 Según Pizarro (2013: 78), la “variación del tabú según parámetros sociales y contextuales se sustenta en ideologías lingüísticas que definen, entre otros, qué temas y formas de expresión son adecuados a cada situación", lo que está en la base, sin duda, del empleo de elementos tabú, disfemísticos o eufemísticos, con distintas funciones comunicativas. 
Sin perder de vista las aportaciones que, con diferentes objetivos, atendiendo a distintos niveles de lengua y desde diversas disciplinas, nos han permitido llegar al momento en el que nos encontramos, desde un enfoque interdisciplinar sociopragmático, ofrecemos, a continuación, una aportación particular al conocimiento del uso y funcionamiento de elementos y expresiones lingüísticos que hacen referencia a realidades tabuizadas, de manera concreta, en el habla de Madrid, y de la incidencia que tienen en ello determinados factores sociales (sexo, edad, nivel de instrucción y clase social), con objeto de conocer el rendimiento funcional en discurso oral de la expresión del tabú y averiguar si existen patrones sociopragmáticos.

\section{METODOLOGÍA DE LA INVESTIGACIÓN: EL CORPUS ORAL Y LAS VARIABLES DE ESTUDIO}

Como acabamos de resumir, el estudio del tabú lingüístico tiene una larga tradición; no obstante, hasta muy recientemente, las investigaciones se realizaban por introspección, tenían como base textos escritos, con frecuencia literarios, o disponían de corpus específicos. Tales trabajos, de corte teórico y descriptivo, realizados habitualmente a través de análisis cualitativos, nos han proporcionado conocimientos de gran interés, valía e importancia sobre el tabú lingüístico, sus tipos, funciones y finalidades y los recursos lingüísticos que se emplean para su expresión, pero no han informado lo suficiente sobre la frecuencia de uso de la expresión lingüística misma del tabú (con respecto a las diferentes esferas interdictas), de las estrategias y los recursos lingüísticos que se emplean, de las funciones comunicativas y finalidades para las que se producen, ni de la incidencia que en todo ello tiene la caracterización social del hablante y la situación de uso de la lengua. Para contar con análisis cuantitativos que permitan conocer la frecuencia de uso y el rendimiento funcional de las expresiones lingüísticas de conceptos y realidades tabuizadas, así como sus condicionamientos sociolingüísticos, y tal es nuestro propósito, consideramos necesario partir de datos de producción oral, de corpus como los que se recogen o se han recogido en los estudios sociolingüísticos.

La mayoría de los estudios realizados desde la sociolingüística, centrados en variación formal, iniciados por H. López Morales (1990, 2001, 2005) y continuados por Martínez Valdueza (1995), Danbolt Drange (1997), Calvo Shadid (2008) y, aunque con una metodología diferente, por Fernández de Molina (2014), se han llevado a cabo a partir de cuestionarios específicos 
y entrevistas dirigidas, con el objetivo de conocer qué expresiones de determinados conceptos tabú, fundamentalmente relacionados con el sexo ${ }^{11}$, muestran prohibiciones o limitaciones de uso en correlación con variantes de variables situacionales y sociales. Recientemente, desde la sociolingüística cognitiva, Pizarro (2013) ha realizado un estudio sobre variación a nivel conceptual, centrado también en el tabú sexual, a partir de un corpus específico creado para la investigación, que completa, en parte, los estudios previos, avanza en el establecimiento de una base teórica y metodológica adecuadas, y confirma la incidencia de factores sociales, situacionales y cognitivos en el uso de la expresión del tabú.

El trabajo que estamos llevando a cabo se enmarca en el macroproyecto internacional conocido como "Proyecto para el Estudio Sociolingüístico del Español de España y América (PRESEEA)"12 y, por tanto, tiene como objetivo general conocer patrones sociopragmáticos a partir de las producciones de los hablantes en entrevistas semidirigidas. Por las características de los corpus PRESEEA, que al ser orales, de registro medio de lengua, no presentan un uso abundante de expresiones lingüísticas referidas a realidades tabuizadas, no podemos llevar a cabo estudios completos de variación onomasiológica conceptual similares al realizado por Pizarro $(2013)^{13}$ y, por tanto, nuestra investigación se centra en conocer cuáles son las expresiones lingüísticas que hacen o que han hecho referencia a realidades tabú, de las diferentes esferas consideradas tradicionalmente como interdictas, que se utilizan en discurso oral semiformal, con qué función comunicativa y finalidad pragmática se emplean hoy en día y en qué proporción aparecen, y si existen condicionantes sociolingüísticos o sociopragmáticos que nos permitan hablar de patrones y que confirmen o completen los hallazgos de López Morales para Puerto Rico, Martínez Valdueza para Las Palmas de Gran Canaria, Danbolt Drange

11 Martínez Valdueza (1995) trabaja también con algunos elementos de la esfera escatológica. En el caso del trabajo de Fernández de Molina (2014), realizado a partir de un cuestionario modelo para el estudio de la norma culta, la investigación no se circunscribe únicamente a la esfera sexual, sino que se enfoca desde un campo semántico y no una esfera, el cuerpo humano, y abarca, así, elementos diversos de la esfera sexual, la escatológica y la social.

12 Véase F. Moreno Fernández (1996, 2005 y 2006) y F. Moreno Fernández, A. M. Cestero, I. Molina y F. Paredes (2000) y Cestero (2012).

13 Las realidades tabuizadas no se expresan lingüísticamente con frecuencia, lógicamente, dada su naturaleza. Eso hace que su aparición en corpus orales no especializados sea reducida, lo que limita las posibilidades de estudio. Por ello, Pizarro (2013) recoge un corpus ad hoc para el estudio multidimensional, desde la semántica onomasiológica, del tabú sexual. Sin embargo, nuestro interés es otro: conocer el uso real de la expresión del tabú en un registro medio de lengua, es decir, conseguir datos de su rendimiento funcional natural en el habla. 
para Viña del Mar, Calvo Shadid para Costa Rica y Fernández de Molina para Mérida, o los de Pizarro, también para Madrid.

Para conseguir los objetivos propuestos, no trabajamos únicamente con cuestionarios, como hicieron López Morales, Martínez Valdueza y Calvo Shadid, sino que partimos del análisis cualitativo y cuantitativo de un subcorpus del corpus oral PRESEEA-Madrid ${ }^{14}$, que nos ha permitido conocer lo que acontece de forma natural en interacción oral, en un registro medio de lengua, y seguiremos con el estudio de los resultados obtenidos en la aplicación de un cuestionario, diseñado para esta investigación, que sigue el modelo de los empleados en los estudios sociolingüísticos precedentes y se ha recogido en los mismos distritos de Madrid con objeto de avanzar en el conocimiento a partir del análisis de la percepción que tienen los hablantes de cómo actúan al respecto en registros formales, medios e informales ${ }^{15}$. En este trabajo, presentamos el estudio del corpus oral llevado a cabo, comenzando por la metodología empleada, y, de manera especial, por el establecimiento de variables y variantes de estudio, y terminando con los hallazgos más significativos.

\subsection{El CORPUS ORAL: PRESEEA-MADRID}

El corpus estudiado para conocer el uso, rendimiento funcional y condicionamientos sociolingüísticos de la expresión del tabú es PRESEEAMadrid. Siguiendo los criterios metodológicos del PRESEEA, las muestras están seleccionadas partiendo de una estratificación de la población en función del sexo, la edad y el nivel de estudios de los informantes, y posestratificadas en base a su clase social y modo de vida. Tal y como se requiere por los criterios generales, para obtener una información adecuada sobre los usos lingüísticos de nuestra comunidad, se utilizó la encuesta semidirigida establecida en el macroproyecto, que se estructura a través de determinados módulos temáticos (el tiempo, lugar donde se vive, familia y amistad, costumbres, peligro de muerte, anécdotas importantes en la vida, deseo de mejora económica), lo que permite reunir discursos de distintos

\footnotetext{
14 Véase Cestero, Molina y Paredes (2012), Molina, Paredes y Cestero (2014) y Paredes, Cestero y Molina (2015).

15 En Cestero (2015) puede obtenerse información más completa de la investigación que estamos llevando a cabo, en sus dos fases: el estudio de corpus oral, que es el que aquí presentamos, y la aplicación y el análisis de un cuestionario específico, diseñado y aplicado ya, que estamos codificando y analizando.
} 
tipos (descripciones, argumentaciones, narraciones, discurso hipotético, transacciones conversacionales) ${ }^{16}$ y controlar los temas que, en algunos casos, favorecen, incluso, la alusión a realidades y conceptos tabú, así, el módulo en el que se habla de la familia y la amistad, o el de anécdotas importantes en la vida, permite la aparición de elementos de la esfera sexual y el módulo dedicado a peligro de muerte y al lugar donde vive (cómo era y cómo ha cambiado) favorece la aparición de elementos de la esfera mágicoreligiosa y de la social.

La investigación ha sido realizada sobre un subcorpus compuesto por 35 minutos (empezamos a analizar a partir del minuto 5 de cada entrevista y lo dejamos en el 40) de 36 entrevistas, 18 del distrito de Salamanca, considerado de clase media y media alta, y 18 del distrito de Vallecas, considerado de clase media y media baja ${ }^{17}$. Hemos analizado el habla de un hombre y una mujer por cada grupo de edad y nivel de instrucción establecidos, que vive en cada uno de los distritos, lo que supone veintiuna horas de grabación del corpus PRESEEA-Madrid.

\subsection{VARIABLES Y VARIANTES DE INVESTIGACIÓN}

La perspectiva desde la que se está llevando a cabo la investigación sobre la expresión lingüística del tabú combina el análisis de la conversación, la pragmática y la sociolingüística, sin olvidar, lógicamente, las aportaciones que se han hecho sobre el tema desde la semántica léxica y la pragmáticacognitiva y teniendo en cuenta la orientación sociolingüístico-cognitiva que ha puesto en marcha Pizarro (2013). Para ello, se ha establecido una nómina de variables y variantes (lingüísticas, pragmáticas y sociales), perfilada a partir de los análisis cualitativos efectuados, que permite estudiar el fenómeno desde múltiples dimensiones y que detallamos a continuación:

1. Forma. Términos y expresiones lingüísticas, que han aludido o aluden a conceptos o realidades interdictos, empleados en el corpus oral. Llevamos a cabo una sistematización esencial y mínima ${ }^{18}$.

16 Véase http://preseea.linguas.net.

17 Sobre la entidad social, Madrid, y la caracterización de los dos distritos seleccionados para el corpus PRESEEA-Madrid, diferentes en cuanto a la caracterización social de gran parte de su población, véase Cestero, Molina y Paredes (2015).

18 Con la intención de realizar un estudio completo y profundo de la expresión lingüística del tabú, trabajamos con todas las expresiones (sean lexías o palabras que forman parte 
2. Expresión. Alusión a conceptos o realidades interdictas a través de expresiones consideradas directas y neutras (ortofemismo), directas no neutras (habitualmente asociada con el disfemismo) o indirectas (usualmente asociada al eufemismo) ${ }^{19}$. Consideramos, con Montero (1981), Casas (2012a y 2012b), Pizarro (2013) o Fernández de Molina (2014), entre otros, que no hay términos eufemísticos o disfemísticos, sino usos discursivos en uno u otro sentido que hacen referencia a las realidades de manera neutra, directa o indirecta ${ }^{20} y$ que dependen, en gran medida, de la finalidad para la que se utilicen y de la forma en que se produzcan. Ofrecemos, a continuación, un

de unidades fraseológicas -tomando en su conjunto la unidad-) que, en algún momento de la historia han hecho referencia a conceptos o realidades tabú. Lógicamente, el cruce entre unidades lingüísticas y funciones comunicativas separa de forma automática y clara las unidades que, en la actualidad, hacen referencia a conceptos y realidades tabuizadas (denominadas unidades con función comunicativa "referencial") y aquellas que tienen valores desplazados o cumplen funciones apelativas o expresivas y, en su mayoría, no hacen referencia ya a conceptos o unidades tabuizadas (denominadas unidades "no referenciales" de distinto tipo, tal y como se recoge en la variable de estudio dedicada a las funciones comunicativas).

19 Las definiciones de las diferentes formas de expresión que están en la base de nuestros análisis son las siguiente:

Ortofemismo: utilización de formas lingüísticas directas, neutras, literales, formales o estandarizadas, que se utilizan para nombrar conceptos o realidades tabuizadas y que resultan no marcadas (Allan y Burrige 2006: 31).

Disfemismo: empleo de formas lingüísticas directas para nombrar realidades tabuizadas, que desvelan voluntariamente la relación del término escogido con el referente, por lo que denotan o connotan y resultan, así, marcadas (Allan y Burridge 2006: 31, Pizarro: 2013: 81). Para identificarlas con mayor propiedad, consideraremos una forma directa no neutra, disfemística, si presenta una marca (de vulgar, malsonante, etc.) en el Diccionario de la Real Academia de la Lengua o en algún diccionario de uso del español.

Eufemismo: uso de recursos lingüísticos variados para hacer referencia, de forma indirecta, a conceptos o realidades tabuizadas, por denotación o connotación (Allan y Burridge 2006: 33, Pizarro 2013: 81).

20 Ha de tenerse en cuenta que, si bien hay una relación intrínseca entre expresión neutra, directa e indirecta y ortofemismo, disfemismo y eufemismo, en el caso de unidades que tienen una función comunicativa referencial (es decir, que actualmente se utilizan para hacer referencia a conceptos o realidades tabuizadas), no hay equivalencia exacta cuando la unidad lingüística tiene, en la actualidad, una función comunicativa "no referencial" y en bastantes ocasiones en las que presenta una función apelativa o expresiva. Recuérdese que trabajamos con unidades que han hecho o hacen referencia a conceptos o realidades tabuizadas, de manera que todas aquellas que tienen una función comunicativa "no referencial", es decir, cuyo valor hoy en día es "desplazado" -distinto del original- o que han perdido su valor original quedando como unidades apelativas o expresivas sin contenido referencial, pueden ser expresiones neutras o directas, pero no necesariamente disfemísticas, pues no aluden ya al concepto o a la realidad tabú a la que aludían en su origen, si bien su uso no es el habitual neutro, sino el propio del directo y marcado, generalmente, por utilizarse con una función apelativa o expresiva. 
ejemplo de expresión neutra (ortofemística), uno de expresión directa (y disfemística) y un tercero de expresión indirecta (y eufemística), en los que se alude a un mismo concepto, de manera que se puede apreciar claramente la diferencia existente:

\section{(1) Expresión neutra}

I: [...] y me quedé así mirando / estaba yo de inspector $<$ silencio/ $>$ dice $<$ alargamiento $/>/ /<$ cita $>$ iusted es el jefe? $<$ cita $>$ digo $<$ cita $>$ sí $</$ cita $><$ silencio/ $>$ digo $<$ cita $>$ pues mire / le voy a pedir disculpa ¡buah! // diga usted a los gitanos / que cuando vengan a cargar $<$ silencio/ $>$ que no les tiren piedras $<$ silencio/ $>$ porque ya tienen bastante $<$ silencio/ $>$ porque vienen a cargar las $<$ ininteligible/ $>$ que hacen ustedes // iy por favor! // los excrementos / tírenlos ustedes allí / que tienen ustedes los pozos $<$ silencio/ $>$ tienen pozos / y las basuras // las ponen ustedes aquí /

MADR-VAL_H31_038

\section{(2) Expresión indirecta}

I: tu mujer está en casa / está todo el día<alargamiento/> peleando con niños pequeños $<$ alargamiento/ $>$ todo el día ahí quitando cacas / todo el día fregando / todo el día tal $<$ alargamiento $/>$ y al fina $<$ alargamiento $/>1$ pues yo comprendo que la sensación que tenga es decir $<$ cita $>$ bueno joder soy una chacha $<$ alargamiento $/>$ y encima gratis $</$ cita $>$ es verdad $\mathrm{y}<$ alargamiento/ $>$

MADR-SAL_H23_031

\section{(3) Expresión directa / disfemismo (con valor desplazado)}

I: se hizo sí // pero vamos / los tres saliero<alargamiento/>n bien ilesos no les pasó nada $<$ silencio $/>$ pero el coche desde luego quedó $<$ risas $=$ "I" $/><$ risas = "E" $/>$ hecho un moñigo ¡madre mía! / ¡qué susto! fue la u $<$ palabra_cortada/> la única vez / mm peor que he pasado

MADR-VAL_M21_023

3. Interdicción. Hemos trabajado con una clasificación general, que combina las propuestas de un gran número de investigadores a partir de las expuestas, de forma expresa, por Casas (1986), Montero (1981 y 2000) y Crespo (2007), para la identificación de las formas que aluden a realidades tabú ${ }^{21}$, partiendo de cuatro esferas interdictas básicas -la primera es tabú ancestral y las

21 Encontramos una gran cantidad de clasificaciones diferentes en la bibliografía sobre el tema, dependiendo del tipo de estudio y de la amplitud o profundidad del mismo. Puede verse 
otras tres tabúes sociales ${ }^{22}$ - con distintos componentes cada una: interdicción mágico-religiosa (cuya motivación suele ser el miedo), en la que se distingue entre religión (deidad y otras entidades) y lo sobrenatural, muerte y enfermedad como subesferas tabuizadas ${ }^{23}$; interdicción sexual (motivada por decencia), en la que se diferencia entre partes del cuerpo erógenas o relacionadas con el sexo y ropa que las tapa o desnudez, procesos y fluidos fisiológicos, prácticas sexuales, actos y efectos producto de prácticas sexuales, conductas y lugares, cualidades relacionadas con atracción sexual, condiciones $\mathrm{u}$ opciones sexuales y, especialmente, relaciones socioafectivas asociadas a la práctica sexual, estados producto de tales relaciones y personas implicadas en ellas; interdicción escatológica (ocasionada por pudor), categorizada, a su vez, en actos de evacuación, partes del cuerpo implicadas, residuos escatológicos y, especialmente, lugar para realizar las necesidades físicas, y, por último, interdicción social (provocada por la necesidad de respeto y delicadeza), en la que se atiende a diferencias sociales entre personas (bien económicas o bien laborales), relaciones familiares no siempre deseadas o deseables y estados producto de determinadas relaciones familiares o sucesos, acciones delictivas y sus efectos o entidades relacionadas, acciones no deseables y sus efectos o entidades relacionadas, carácter delictivo, carácter no deseable, defectos físicos o rasgos físicos no deseables, defectos psíquicos, raza, etnia o grupo cultural asociados a comportamientos delictivos y, sobre todo, edad avanzada y no deseable ${ }^{24}$.

una revisión en Calvo (2011) y en Pizarro (2013). Consideramos obras de consulta obligada al respecto Casas (1986), Montero (1981) o Crespo (2007).

22 Es lo que se ha relacionado, a lo largo de la historia del estudio del tabú lingüístico, con interdicción (ancestral) y con tabú (social).

23 Las categorías de cada esfera que aquí distinguimos, tratadas, a su vez, como variantes de una variable más, son las que cuentan con unidades en el corpus manejado, por tanto, no se trata de una nómina cerrada, pero sí, suponemos, de la más rentable en la actualidad.

24 En la investigación sobre la expresión del tabú en el habla de Madrid que estamos llevando a cabo trabajamos solo con esferas consideradas interdictas de forma tradicional, partiendo de la clasificación y los subtipos propuestos por Montero (1981 y 2000), aunque somos plenamente conscientes, como han apuntado ya otros investigadores (Crespo 2007), de que esferas como la mágico-religiosa están, en la actualidad, muy poco tabuizadas y que ha aparecido una esfera político-económica-social, muy poblada ya de elementos y recursos directos e indirectos. No atendemos, pues, a esta esfera que, en los últimos años, ha comenzado a interesar de manera especial en los estudios sobre eufemismo y que se relaciona, de manera directa, con la expresión de conflicto político-social, lo políticamente correcto o incorrecto. 


\section{(4) Esfera mágico-religiosa}

I: ¡pero bueno por Dios! pero ¿tú sabes? </cita $>$ y digo <cita $>$ sí sí yo sé me van a abrir el pecho / que me va $<$ vacilación/ $>$ van a hacer una operación de de educación $<$ vacilación/ $>$ eh circulación extracorpórea y todas estas cosas / ¡claro es que hay que hacerlo! o hacerlo o $<$ vacilación/>o irnos al $<$ vacilación/>a la Almudena como vulgarmente se dice $</$ cita $>/$

MADR-SAL_H32_043

I: hombre luego ya cuando ha muerto es que cuando ha muerto estaba muy delgado y muy mal / que ha muerto de $<$ alargamiento/ $>$ de un cáncer en el hígado y / se ha ido consumiendo

MADR-VAL_M31_042

\section{(5) Esfera sexual}

I: pues eeh porque ahí había $\mathrm{u}<$ alargamiento/ $>$ n un hotel $<$ silencio/ $>$ que $<$ alargamiento/ $>$ era una casa de $<$ alargamiento/ $>$ / de furcias

MADR-SAL_H33_049

I: y entonces pues / siempre hemos estado juntos / pero no <alargamiento/> / pero no revueltos / entonces siempre hemos estado juntos sí / pero no $<$ alargamiento $/><$ risas $=$ "E" $/>/$ no éramos $/$ nunca hemos intimado / pero un día /

MADR-VAL_H11_002

(6) Esfera escatológica

I: entonces pues dices $<$ cita $>$ ijoder! pues seguramente contaminar es malo $</$ cita $>$ independientemente de lo que haga el volcán ¿no? $<$ risas $=$ "I" $/>$ entonces si tú puedes evitar por tu parte $/ /<$ vacilación $/>$ pero también $<$ alargamiento $/>$ / $<$ vacilación $/>$ por lo visto la $<$ alargamiento $/>$ s ¡no sé! lo<alargamiento/> / < vacilación/> un día oí / < vacilación/> comparativamente lo que suponía de $\mathrm{CO}^{2} / /$ los pedos que se puede tirar una vaca /

MADR-VAL_H23_032

\section{(7) Esfera social}

I: sí / se ofendían < silencio/> decía que ellas no eran moras que eran marroquís // <observación_complementaria = "elemento paralingüístico" $\mid><$ ininteligible $/>/ /<$ cita $>\mathrm{N}$ no te ofendas porque $<$ vacilación $/>$ te digo $<$ alargamiento/ $>$ / mora pero no te lo digo en plan de ofensa $/$ te lo digo en plan $<$ ruido $=$ "chasquido boca" $/>$ pues como de dede $/ /$ de que eres marroquí</cita $>$ ella decía <cita $>$ yo soy marroquí // moros son 
los otros $</$ cita $>/ /$ no sé quién serían los otros $<$ silencio/ $>$ ella decía $<$ cita $>$ moros son los otros $</$ cita $><$ silencio/ $>$

MADR-VAL_M21_023

La clasificación manejada que acabamos de presentar sirve de base para organizar las realidades interdictas y los elementos lingüísticos que son objeto de estudio por hacer referencia a ellas. No obstante, como muy acertadamente apunta Pizarro (2013: 74) recordando las consideraciones de Uría (1997), las causas que motivan el tabú son puramente contextuales y no organizan, de forma estable e inamovible, categorías de elementos, de manera que, en determinadas ocasiones comunicativas, puede ser el miedo el que origine el tabú social o sexual, o el respeto el que origine el tabú religioso. Por tanto, es la situación comunicativa la que explica, o determina, en última instancia, el uso de elementos tabuizados o de sustitutos para los mismos, lo que enlaza, de manera directa, con el estudio del tabú lingüístico desde la pragmática, que centra su atención en la función que cumple el uso de los elementos que nos ocupan en la comunicación.

4. Función comunicativa. Teniendo en cuenta las clasificaciones funcionales precedentes, especialmente la apuntada por Martínez Valdueza (1998), y lo que acontece al respecto en el corpus manejado, hemos realizado los análisis cualitativos y cuantitativos distinguiendo entre las siguientes funciones comunicativas: función comunicativa referencial, con la que se utiliza una expresión lingüística asociada a realidad o concepto interdicto para hacer referencia a tal concepto o realidad; función comunicativa de referencia desplazada, mediante la que se emplea una expresión lingüística asociada a una realidad o concepto interdicto con un significado diferente, no relacionado con interdicción; función apelativa, empleo de formas y expresiones para apelar, insultar o injuriar; función expresiva mediante el uso de formas expletivas producidas como exclamaciones interjectivas, sin valor referencial, y función expresiva con utilización de formas expletivas que se insertan en construcciones sintácticas, sin valor referencial, marcando estilo coloquial.

\section{(8) Función referencial}

I: cierto que los países del este // la mayoría bueno por lo que se oye en las noticias $0<$ alargamiento/ $>$ se comenta pues que $<$ alargamiento $>>$ / pueden $<$ alargamiento/ $>$ traer a la mayorí $<$ vacilación $/>$ a $<$ vacilación/ $>$ o a gran parte de $<$ alargamiento/ $><$ vacilación/ $>$ $\mathrm{de}<$ alargamiento/ $><$ vacilación $/>$ de sus compatriotas engañados eh $<$ alargamiento/ $>$ prometiéndoles el oro $<$ alargamiento/ $><$ vacilación $/>$ 
o sea prometiéndoles // cosas que luego no son $\mathrm{y}<$ alargamiento/ $>$ que se encuentran aquí con una situación / mucho peor de la que ellos empe $<$ vacilación/ $>$ esperaban encontrar o se tengan que / buscar trabajo pues o en prostitución $\mathrm{o}<$ alargamiento/ $>$ en cualquier $<$ vacilación $/>\mathrm{o}$ incluso en droga / en cualquier otra situación que no sea la óptima / pero $<$ alargamiento/ $>$ / no tendría por qué ser así //

MADR-VAL_M23_035

(9) Función de referencia desplazada

I: quieren experiencia entonces piden / un año mínimo con experiencia // entonces está un poco jodida la cosa /

MADR-VAL_H13_014

\section{(10) Función apelativa}

I: vamos a llamar así ¿no? que te<alargamiento/>navajea o tal para quitarte / a mi<alargamiento/ $>$ esposa $<$ alargamiento/ $>$ en alguna ocasión ha habido una señora que ya la conoce todo el mundo que esa $<$ entre risas $>$ en la confluencia $<$ risas $=$ "E" $>>$ de Goya con Alcalá $</$ entre_risas $>$ ¡que ya la conocemos todos! ¡es que es tonta además! tonta porque / hace unos días un señor que la vio <cita $>$ tú ¿qué haces aquí? <entre_risas $>$ lárgate $</$ entre_risas $><$ risas $=$ "E"/ $>$ caradura no sé qué $</$ cita $>$

MADR-SAL_H32_043

\section{(11) Función interjectiva}

I: porque es lógico que / <vacilación/>joder que si / <vacilación/> tirar la $<$ vacilación/> el<alargamiento/> aceite // pues / eeh / digamos / reciclar esa agua con ese aceite / jjoder! pues para no sé cuántos litros de agua / pero por otra parte yo trato de ahorrar agua // pues dices $<$ cita $>$ bueno joder pues $<$ alargamiento/ $>/ / \mathrm{o} /<$ vacilación/ $>$ o no hago nada / o as $<$ vacilación/ $>$ o el aceite lo voy a guardar en una botella y me lo voy a llevar ¿no? $</$ cita $>$ porque dices $<$ cita $>$ joder es que si no no hago nada $</$ cita $>/ /$

MADR-VAL_H23_032

(12) Función de marcador de estilo

I: es $<$ vacilación/> entonces pues echaba de menos eso / el provincianismo de decir < cita $>$ ijoder! / ipff! / estamos en el puto pueblo </cita $>$ como suele decirse ¿no? / <simultáneo $>$ entonces $</$ simultáneo $>$

MADR-VAL_H23_032

5. Finalidad pragmático-discursiva. Perfilando las propuestas previas, a partir de las reflexiones y la clasificación final de Casas (2012a y 
$2012 b)^{25}$ y de lo que acontece en nuestro corpus, hemos trabajado con las siguientes finalidades generales con el empleo de expresiones que hacen referencia a realidades y conceptos tabuizados: encubrir, entendida como el uso de elementos o expresiones lingüísticas que aluden de manera indirecta a conceptos o realidades interdictas para evitar la denotación o la connotación negativas de los términos interdictos neutros y directos; atenuar, considerada como la selección de ciertos elementos o expresiones lingüísticas con objeto de rebajar o eliminar la tensión social que supondría el uso de expresiones de referencia directa a realidades interdictas, evitando, así, amenazas a relaciones sociales o a las imágenes del emisor o del receptor; enfatizar o realzar expresivamente (realidades interdictas o no), mediante el uso de expresiones o términos que han aludido o aluden a una determinada realidad o concepto considerado socialmente denostado (con objeto de revalorizarlo), y, por último, hacer referencia a conceptos o realidades interdictos con una finalidad puramente informativa.

25 Crespo Fernández (2007) también habla de funciones y finalidades, pero no en el mismo sentido que nosotros de funciones comunicativas y finalidades pragmáticas. Las variables y variantes con las que trabajamos aquí están reelaboradas a partir de la propuesta de Crespo Fernández (2007) y, especialmente, de la de base pragmático-cognitiva de Casas (2012a y 2012b). Obsérvese que es la finalidad con la que se utiliza la que, junto con la forma de emisión, como veremos más abajo, permite establecer si una expresión lingüística es ortofemística, eufemística o disfemística, pues, como ha apuntado Casas en varias ocasiones ya (2012a y 2012b), no debemos hablar de términos eufemísticos o disfemísticos, sino de usos eufemísticos o disfemísticos de las expresiones lingüísticas, sobre la base de determinados procesos cognitivos de conceptualización de las realidades interdictas. En esta idea redundan los apuntes de García Platero (2010: 813) en los que reconoce que "las unidades léxicas catalogadas inicialmente como disfemísticas no actualizan su carácter peyorativo, en la medida en que intervienen razones de interrelación entre los hablantes de un grupo determinado", lo que explica el empleo de palabras malsonantes, habitualmente utilizadas para insultar, como apelativos cariñosos o finalidades afectivas. Tales casos revelan la imposibilidad de atender unidades discretas específicas para cada variedad funcional y la necesidad de enfocar su estudio atendiendo a la finalidad, que se consigue, en ocasiones, mediante un discurso más expresivo, coloquial, etc. Nosotros, teniendo en cuenta estas consideraciones, preferimos hablar de expresión neutra, directa e indirecta de conceptos o realidades tabú y no ceñirnos al empleo de los conocidos términos disfemismos y eufemismos. En relación con ello, no queremos dejar de reproducir aquí las acertadas palabras de Montero sobre el eufemismo (2000: 552): "Ya no se teme la palabra, sino las asociaciones y las connotaciones que despierta. De lo que se huye por medio del eufemismo es de la representación obscena, sucia o molesta que el ser, función, objeto o miembro transmite a la palabra". 


\section{(13) Encubrir}

I: pues mira mi marido ya no está pero<alargamiento/> / era un $<$ alargamiento/ $>$ ¿físicos?

E: sí bueno físicos y también de carácter si quieres lo que quieras

I: ¡bueno! pues / físicamente / era $<$ alargamiento/ $>$ mmm una persona con $<$ vacilación $/>$ de una $<$ alargamiento/ $>$ un metro setenta rubio con el pelo rizado

MADR-SAL_M32_047

(14) Atenuar

I: ¿mi madre? // es morena / tiene el pelo muy largo / un poquito rellenita un $<$ vacilación/ $>$ más o menos del nivel de mi estatura los ojos verdes oliva la carita redonda y muy alegre muy<alargamiento/ $>$

MADR-VAL_M11_005

\section{(15) Enfatizar}

I: ya pero es un trabajo cojonudo ¡coño! si lo quiero hacer / tendré que estudiar $<$ silencio/ $>$

MADR-SAL_H11_001

(16) Informar

I: tengo cuatro hijos sí / < simultáneo $>$ y un $</$ simultáneo $>$

$\mathrm{E}:<$ simultáneo $>$ ¿y? $</$ simultáneo $>$

I: aborto $<$ entre_risas $>$ entre medias $</$ entre_risas $>/ /$

MADR-VAL_M33_053

6. Emisión de expresión en discurso referido o no referido. Hemos tenido en cuenta si las expresiones para aludir a realidades y conceptos tabuizados se producen en la reproducción de palabras de otras personas o situaciones, con objeto de comprobar si la emisión en citas, normalmente de situaciones con registros de lengua informales, es relevante.

7. Forma de producción. Dado que trabajamos con la expresión del tabú, es de suponer que su forma de producción esté marcada mediante el empleo de indicadores paralingüísticos o lingüísticos que incidan, significativamente, en su función y finalidad y que muestren la intención comunicativa que tiene el hablante al elegir o emplear una expresión lingüística determinada para hacer referencia a un 
concepto o realidad tabú ${ }^{26} \mathrm{y}$, a su vez, el vestigio que queda de la interdicción misma. A este respecto, hemos considerado relevante analizar tanto el volumen de emisión como la utilización de varios indicadores en el contexto mismo de producción que marcan la expresión interdicta, trabajando con las siguientes variables que conciernen a la forma de producción:

7.1. Volumen de emisión de las expresiones referidas a realidades interdictas. Hemos distinguido cuatro posibilidades: volumen medio normal (no marcado), volumen bajo, volumen alto y volumen muy alto o enfático.

7.2. Pausas. Con objeto de conocer posibles marcas características de la producción en interacción de formas que aluden a realidades y conceptos interdictos, hemos atendido, además, a si los emisores hacen alguna pausa previa a la emisión de la expresión, alguna pausa posterior, pausa previa y posterior como indicadoras de la emisión de unidad no apropiada, o no producen pausas.

7.3. Risa. Por otro lado, hemos constatado, si los informantes producen risa previa a la emisión de expresiones que aluden a realidades o conceptos interdictos, risa posterior, risa previa y posterior, como marcador de contexto con interdicción, o no ríen.

7.4. Alargamiento de sonidos. Hemos tenido en cuenta en los análisis si se produce arrastre o alargamiento de sonidos en la producción de la expresión interdicta, antes, después o antes y después, o si no se produce, bajo el convencimiento de que se trata de un signo paralingǘstico que puede indicar duda e inseguridad y, con ello, rebajar el efecto de la propia emisión. Podrá ser un indicador de restos de interdicción e, incluso, un atenuador $-\mathrm{o}$ intensificador.

7.5. Vacilación. Con el mismo objetivo que en el caso anterior, analizamos si las muestras de vacilación en el contexto inmediato de la emisión de la expresión del tabú -antes o después, antes y después-supone un vestigio de la existencia de interdicción o rebaja o, incluso, intensifica el carácter interdicto de la expresión misma. 7.6. Justificaciones y excusas. Hemos tenido en cuenta, también, si los hablantes emiten justificaciones o excusas por la producción

26 De manera muy acertada, en mi opinión, ya trabaja con esta variable Fernández de Molina en su estudio sobre eufemismos y disfemismos en el campo semántico del cuerpo humano (Fernández de Molina 2014). La autora tiene en cuenta especialmente la entonación para establecer el carácter final de las expresiones que analiza. 
de elementos interdictos antes de usar expresiones que aluden a realidades o conceptos interdictos, después, antes y después, o no producen excusas.

7.7. Modificadores de cantidad o cualidad. Hemos atendido, además, a la utilización o no de diminutivos y otros modificadores, como tácticas minimizadoras o difuminadoras de la cantidad o la cualidad, que pueden resultar especialmente significativos en la expresión lingüística del tabú ${ }^{27}$.

8. Temática. Siguiendo modelos establecidos en los análisis del PRESEEA, hemos tenido en cuenta la emisión de expresiones que hacen referencia a conceptos y realidades tabú en el desarrollo de temas especializados y no especializados (técnicos/no técnicos), con objeto de conocer si tiene incidencia en su frecuencia de uso.

9. Modalidad textual. También siguiendo el modelo establecido en los análisis del PRESEEA, hemos atendido a la incidencia de la modalidad textual en la producción de expresiones para hacer referencia a realidades interdictas, distinguiendo entre las siguientes modalidades: argumentación, exposición, narración y descripción.

10. Caracterización social del hablante

10.1. Edad. El primer factor social que tenemos en cuenta es la edad. Siguiendo los criterios del PRESEEA para la recogida de corpus, trabajamos con los siguientes grupos de edad: primera generación, de entre 20 y 34 años; segunda generación, de entre 35 y 54 años, y tercera generación, de 55 años o más.

10.2. Sexo. Como es habitual en los estudios sociolingüísticos, distinguimos entre producciones realizadas por hombres y por mujeres.

10.3. Nivel de instrucción. Tal y como se recoge en los criterios generales de PRESEEA, los individuos de nuestra muestra tienen uno de los tres niveles de instrucción establecidos: estudios primarios, estudios secundarios o estudios superiores.

10.4. Clase social. Como factor de posestratificación, y, por tanto, sin que haya un número igual de informantes de las distintas categorías,

27 Son de gran interés a este respecto, entre otros, el trabajo de Chamizo 2008 y el de García Platero (2010), en los que se muestra el uso de afijos, especialmente diminutivos, que confieren carácter eufemístico o disfemístico a una expresión lingüística inicialmente de valor neutro. 
hemos trabajado con la clase social, a partir, por un lado, del barrio en el que viven los informantes (distrito de Salamanca o distrito de Vallecas) y de la caracterización de los hablantes en cuatro clases básicas: baja, media baja, media y media alta, a partir de un procedimiento que tiene en cuenta, en proporciones diferentes, la profesión y los ingresos de cada sujeto ${ }^{28}$.

10.5. Modo de vida. Finalmente, también como factor de posestratificación, y sin que haya equilibrio en el número de informantes de cada grupo establecido, hemos trabajado con el modo de vida de los informantes, determinado, siguiendo los criterios de PRESEEA, por estar enfocado hacia el ocio, la familia o el trabajo ${ }^{29}$.

Ofrecemos, a continuación, un resumen de los resultados generales más relevantes obtenidos en los análisis cualitativos y cuantitativos realizados.

\section{LA EXPRESIÓN DEL TABÚ EN EL HABLA DE MADRID}

Los objetivos marcados para la parte de la investigación de la que aquí damos cuenta son varios: conocer el uso y la frecuencia de aparición de expresiones lingüísticas que hacen referencia a conceptos o realidades interdictas pertenecientes a las esferas tabú establecidas habitualmente en la bibliografía (mágico-religiosa, sexual, escatológica y social), así como

28 Siguiendo los criterios metodológicos del PRESEEA, la clase social de los sujetos se establece a partir de su profesión y sus ingresos anuales. Como es habitual en sociolingüística variacionista, se realiza una operación simple, con ponderación de la puntuación que tiene el sujeto en las entidades manejadas. Con respecto a la profesión, se distinguen 8 variantes: obreros sin cualificación, estudiantes, obreros con cualificación, empleados medios, pequeños empresarios y autónomos, medianos empresarios, profesionales libres y altos directivos y empresarios; con respecto a los ingresos, se tienen en cuenta tres intervalos básicos: hasta $9000 €$, de $9000 €$ a $21000 €$ y más de $21000 €$, y se anota, también, si no dispone de ingresos. Para obtener una información más detallada puede consultarse PRESEEA (2003).

29 Anotamos, además, si la emisión supone la repetición de una expresión previa, producida en el contexto inmediato, con objeto de comprobar si tal repetición es un recurso enfatizador. Tenemos en cuenta, por otro lado, cuál es el informante que emite cada expresión, por si, de acuerdo con los estudios de corte sociolingǘstico-cognitivista que se están realizando en la actualidad, puede incidir en patrones de comportamiento y, con el fin de facilitar comparaciones intercomunitarias más adelante, apuntamos, también, si el informante es castellanohablante monolingüe o bilingüe, madrileño o inmigrante español y la comunidad en la que vive (Madrid). 
el uso y la frecuencia de aparición de expresiones directas, marcadas o no, o indirectas para hacer referencia a conceptos y realidades tabuizados y los factores de producción y contexto lingüístico relacionados con ellos; documentar las funciones comunicativas y las finalidades pragmáticas con las que son utilizadas, en interacción oral, en registro medio de lengua, las expresiones lingüísticas que aluden o han aludido a conceptos o realidades interdictas y constatar la existencia de patrones sociopragmáticos ${ }^{30}$.

Para la consecución de tales objetivos, hemos analizado, cualitativa y cuantitativamente, 21 horas de grabación del corpus PRESEEA-Madrid; en ellas, hemos documentado 1478 unidades lingüísticas que aluden o han aludido a conceptos o realidades tabuizadas. La mayoría, el 56,6\% (836 casos) pertenece a la esfera social, el 19,4\% (286 casos), a la sexual, el $19,5 \%$ (288 casos), a la religiosa y el 4,6\% (68 casos), a la escatológica. Los datos, condicionados, sin duda, por el corpus manejado - conversación semidirigida, en registro medio de lengua-, muestran que el paso del tiempo ha disminuido considerablemente el peso y el efecto del tabú, pero quedan vestigios de interdicción, que se pueden observar en la baja frecuencia de aparición, en discurso oral, de elementos lingüísticos que aluden a entidades escatológicas, religiosas o sexuales, así como en su forma de producción.

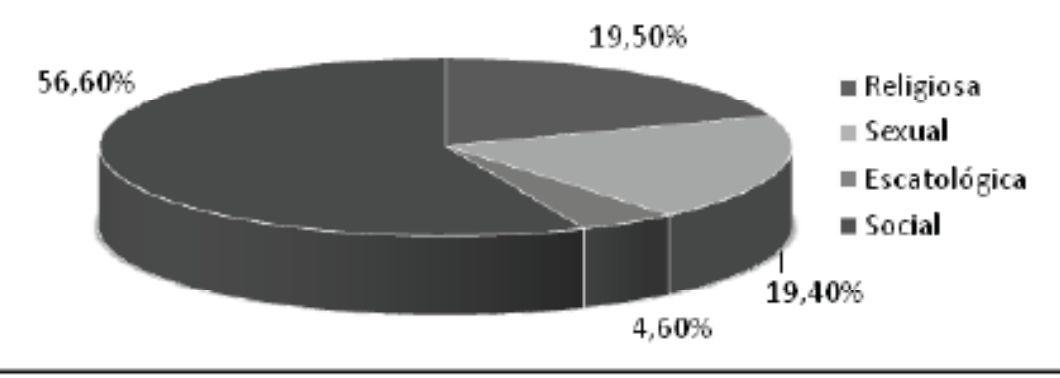

Gráfico 1. Expresión del tabú y esferas

Es indicio de la interdicción que pesa sobre las expresiones que nos ocupan, además, el hecho de que, en discurso oral, la mayor parte de las unidades léxicas que se eligen para hacer referencia a entidades tabú sean directas

30 Por razones de espacio, no podemos ofrecer aquí los resultados de todos los análisis realizados en el estudio del corpus. Hemos optado por proporcionar ahora los datos generales que consideramos de mayor interés y dejar para un trabajo extenso posterior toda la información procedente del análisis lingüístico y sociolingüístico de la expresión del tabú a partir de las diversas esferas o categorías conceptuales, así como de las unidades de uso frecuente. 
y neutras, no marcadas, pues así tiene lugar en el 61,9\% de los casos (915 ocurrencias), o indirectas -eufemísticas-, como ocurre en el 26,8\% de las ocasiones (396 ocurrencias). Encontramos únicamente 167 expresiones directas y marcadas (disfemísticas), que constituyen el 11,3\% de los casos estudiados.

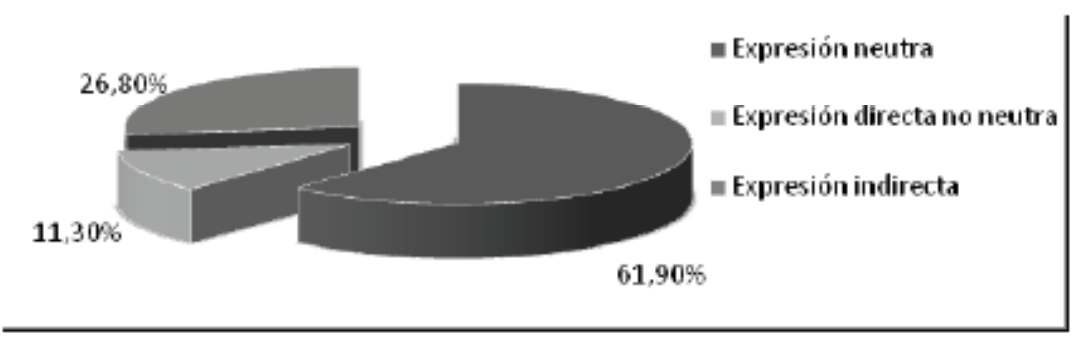

Gráfico 2. La expresión del tabú

La forma de producción es un aspecto relevante en el estudio que estamos llevando a cabo. Hemos apuntado más arriba que lo más habitual, en discurso oral semiformal, es el empleo de expresiones neutras, seguido por el de las indirectas y, muy de lejos, por el de las directas. Sin embargo, la forma de producción permite comprobar la interdicción que pesa sobre las expresiones que nos ocupan. Así, en 156 ocasiones, los ortofemismos se producen con volumen bajo y en 52 ocasiones se emiten disfemismos con un volumen mucho más bajo de lo habitual. Por otro lado, aunque el número de expresiones directas no neutras que aparecen en el corpus es bastante bajo, la emisión de 36 expresiones ortofemísticas y de 5 eufemísticas con volumen alto o tono enfático nos permite afirmar que, como indica, entre otros, Casas (2012a y 2012b), no existen formas ortofemísticas, disfemísticas o eufemísticas, sino usos discursivos determinados. El mismo efecto de reducción que el volumen, presenta la producción con marcas paralingüísticas (alargamientos y vacilaciones) o lingüísticas de distinto tipo (modificadores de la cualidad o cantidad y justificaciones). En el primero de los casos, es significativo que hayamos documentado 262 casos de ortofemismos en contextos en que se producen alargamientos y 115 , en contextos con vacilaciones; de la misma manera, es de gran interés el hecho de que, en 44 ocasiones, se produzcan alargamientos de sonidos en el contexto en que se emiten disfemismos y, en 18 ocasiones, aparezcan vacilaciones. En el segundo de los casos, se han identificado 28 ejemplos de ortofemismos modificados con diminutivos o difuminadores y 3 de disfemismos, así como 2 ortofemismos y 2 disfemismos excusados o justificados. 
En relación con estos últimos datos están los hechos de que se enmarquen con pausas 330 ortofemismos y 165 eufemismos, y con risa, 34 ortofemismos y 22 eufemismos, que pueden rebajar el acto que se produce, pero también enfatizar, confiriendo carácter directo y marcado a ciertas expresiones habitualmente neutras o indirectas. Sin duda, la forma de producción, pues, es indicador de la interdicción a la que está sujeta la expresión lingüística y permite comprobar que es la finalidad la que determina la estrategia seleccionada: ortofemismo, disfemismo o eufemismo.

El estudio de las funciones comunicativas y de las finalidades pragmáticas ha resultado, también, de gran interés. Lo más habitual es que las expresiones que aparecen en el corpus sean "referenciales", es decir, aludan a conceptos o realidades interdictas; así es en el 87,1\% de los casos (en 1287 ocasiones). En su mayoría, se emplean para informar (65\%), si bien encontramos un uso relativamente frecuente de expresiones para encubrir (15\%) y para atenuar (14\%), y un empleo mucho menor para enfatizar (6\%). Estos datos apuntan, pues, el escaso uso de disfemismos en discurso oral, en registro medio de lengua, e indican, de nuevo, la existencia de interdicción en las unidades lingüísticas analizadas, con la aparición de un 30\% aproximado de expresiones indirectas.

En el habla semiformal de Madrid, hemos documentado, además, un número considerable de expresiones lingüísticas que presentan pérdida de la referencia interdicta originaria, es decir, que no aluden a conceptos o realidades tabú, sino que se utilizan con un contenido desplazado, como apelaciones, como expresiones interjectivas y como marcadores de estilo. En total, el número de casos de unidades empleadas con función "no referencial" es 191, lo que constituye el 13\% de la muestra y, en su mayoría, se utilizan para enfatizar, y los hablantes eligen expresiones directas. La mayor proporción de aparición de estos casos la tienen las expresiones interjectivas (103 casos, el 7\% del total). Es relativamente frecuente, también, encontrar expresiones con función comunicativa de referencia desplazada ( 74 casos, el $5 \%$ del total). Es peculiar encontrar en discurso oral semiformal expresiones apelativas, en su mayoría insultos, que tienen como finalidad, una vez más, la enfatización (12 casos, el 0,8\% del total), y resulta prácticamente inexistente el uso de estas expresiones como marcador de estilo en el registro de lengua que hemos analizado, ya que aparecen solo 2 casos, el $0,1 \%$ del total ${ }^{31}$.

\footnotetext{
31 El análisis de la variable "producción o no en discurso referido" nos ha permitido constatar que, cuando se emplean expresiones referidas a conceptos o realidades interdictas en citas, suelen tener la finalidad de enfatizar y, por ello, la proporción de aparición de expresiones directas en tal contexto es mucho mayor de lo habitual (el $40 \%$ del total de las emisiones
} 


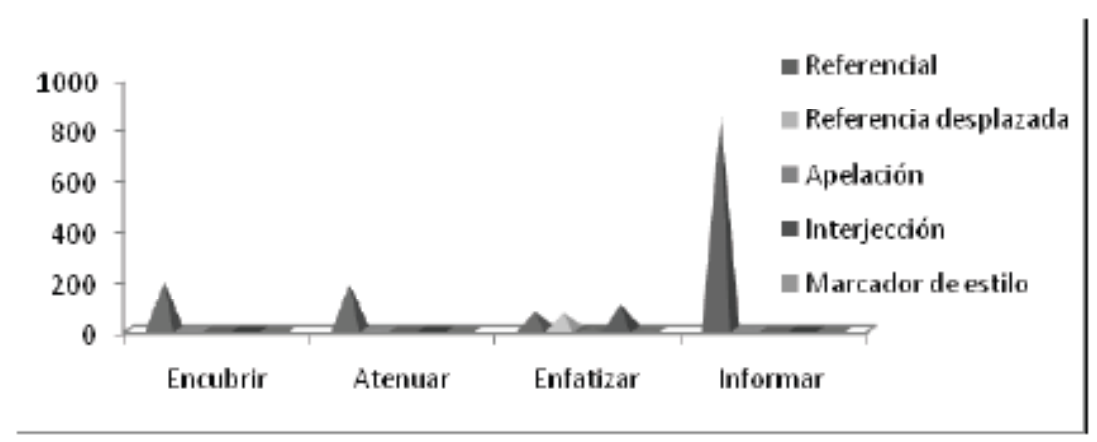

Gráfico 3. Expresión del tabú: función y finalidad

Los análisis cualitativos y cuantitativos realizados nos han permitido, además, conocer la existencia de tendencias de uso sociopragmáticas. De manera general, podemos decir que las mujeres madrileñas, en su habla semiformal, emplean más expresiones que aluden a conceptos o realidades tabú que los hombres (836 casos, frente a 642; el 57\% frente al 43\%), si bien lo hacen habitualmente con una estrategia neutra (572 casos) o indirecta (214 casos), frente al mayor uso de expresiones directas que, en proporción, hace el hombre (117 casos).

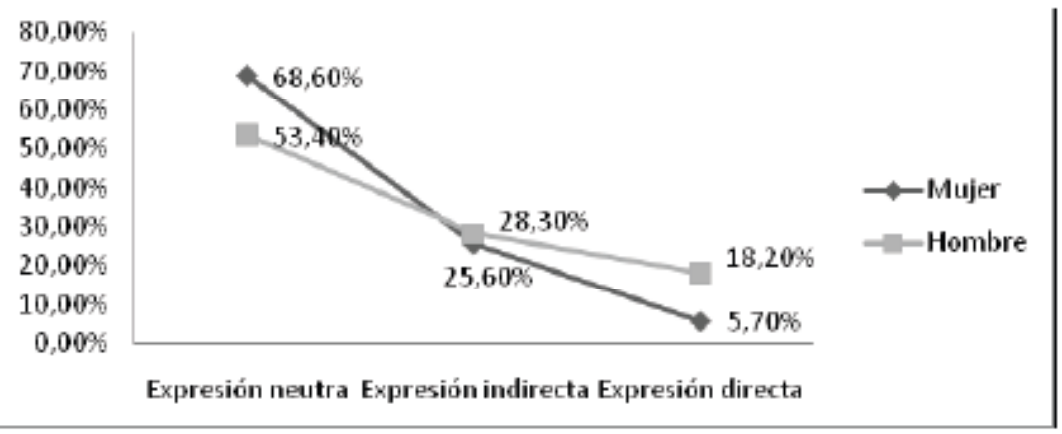

Gráfico 4. La expresión del tabú: sexo

Relacionado con los datos que acabamos de dar está el hecho de que la mujer emplee la expresión de tabú habitualmente para informar y que el

producidas en discurso referido). Las variables relacionadas con la especialización temática y la modalidad textual no han arrojado datos de interés. 
hombre, proporcionalmente, use la expresión del tabú bastante más que la mujer para enfatizar.

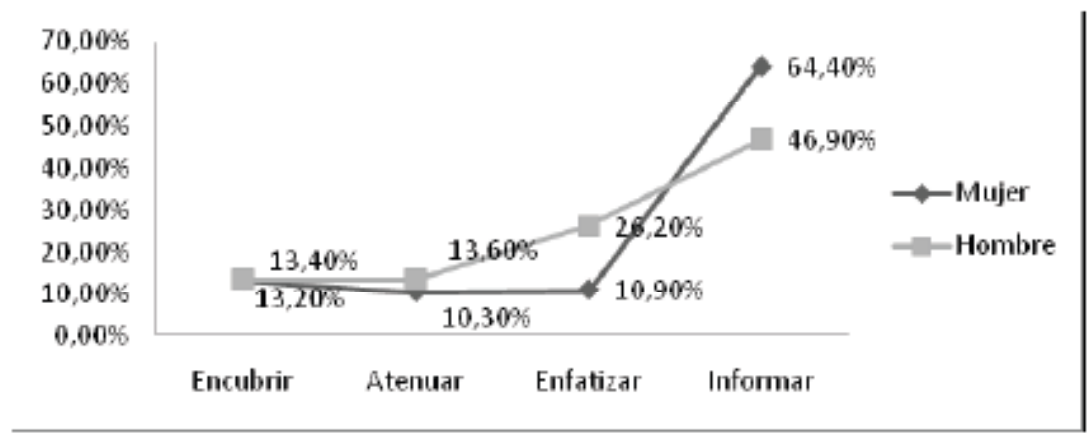

Gráfico 5. Finalidad de la expresión del tabú: sexo

Resulta interesante, además, el hecho de que la mujer utilice más expresiones de la esfera mágico-religiosa y de la social que el hombre, y que este último haga uso de un número mayor de expresiones de la esfera sexual y de la escatológica que la mujer.

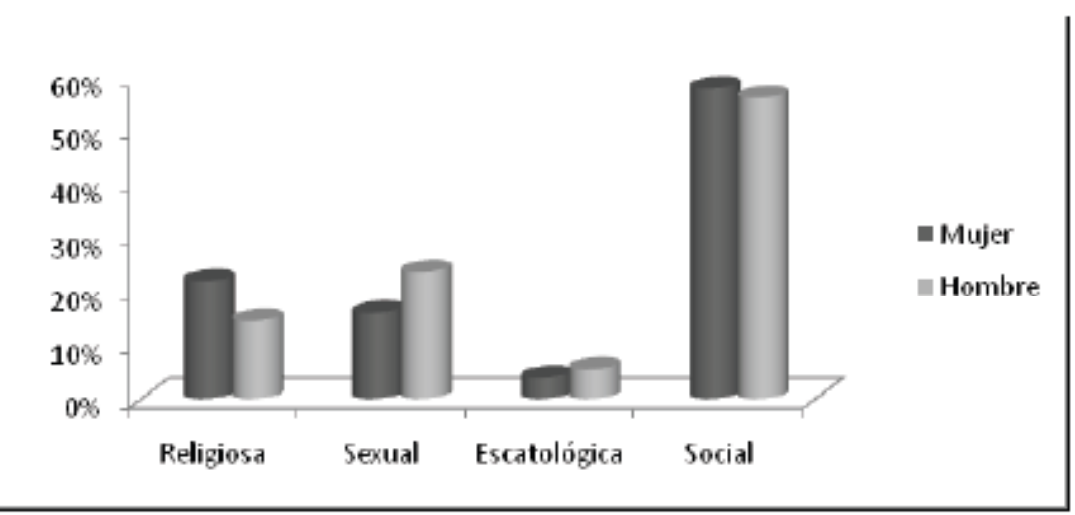

Gráfico 6. Esferas: sexo

La edad de los informantes ha resultado ser también un factor de incidencia significativa en la expresión del tabú. Las personas de 55 años o más son los madrileños que más uso hacen, en su discurso semiformal, de las unidades lingüísticas que nos ocupan (548 casos, el 37\%), seguidas muy de cerca por los adultos de entre 34 y 54 años (536 casos, 36,3\%) y muy de lejos de los jóvenes (394 casos, el 27\%). Todos hacen un mayor uso de expresiones 
neutras e indirectas, pero resulta interesante que sean los adultos los que hagan un empleo más destacado de expresiones directas ( 75 casos, frente a 55 de los jóvenes y a 37 de los mayores).

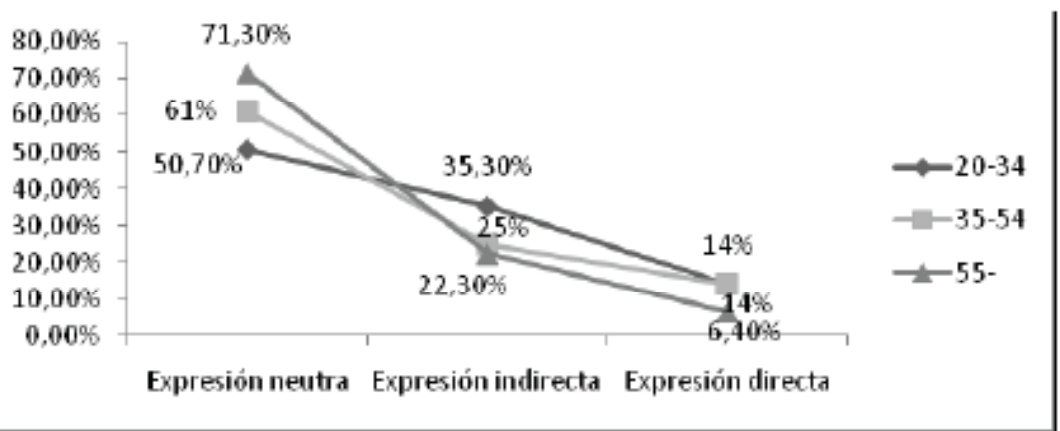

Gráfico 7. La expresión del tabú: edad

En relación con los últimos datos, son los adultos los que más utilizan las expresiones que aluden a conceptos o realidades interdictas con el fin de enfatizar, si bien, en proporción, los jóvenes las utilizan con esta función de manera más destacada (en un $20,5 \%$ de las ocasiones, frente al $17,3 \%$ de los adultos y al 15,5\% de los mayores).

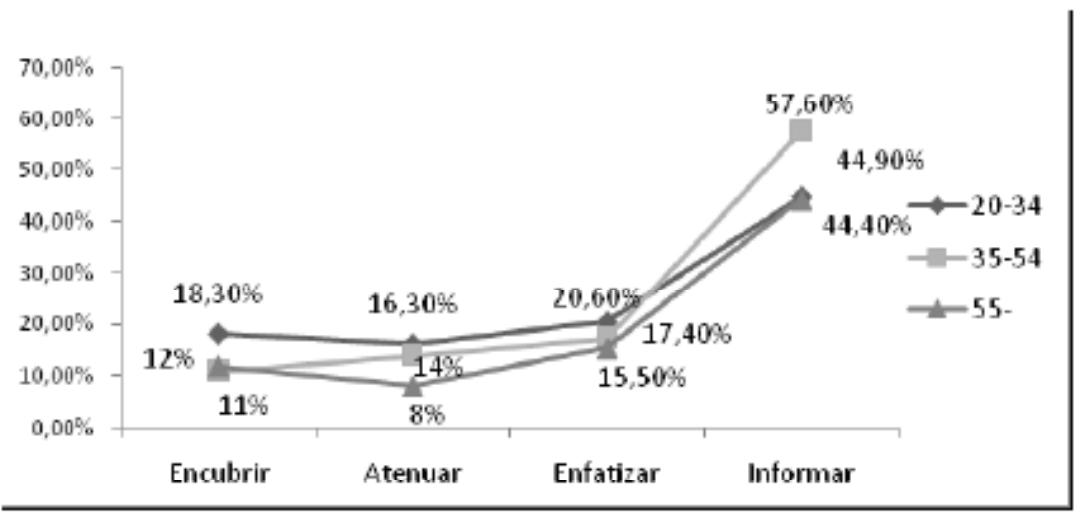

Gráfico 8. Finalidad de la expresión del tabú: edad

Por último, es destacable que los jóvenes sean los que más hayan empleado, en nuestro corpus, expresiones de la esfera sexual (30,7\%, frente al $19,5 \%$ de los adultos y al $10,7 \%$ de los mayores) y de la escatológica (7,6\%, frente al 3,2\% y al 3,8\%, respectivamente), que parecen ser sobre las que más pesa el tabú, los mayores de la mágico-religiosa $(25,4 \%$, frente al $16,4 \%$ de los 
adultos y al $13,5 \%$ de los jóvenes) y los adultos, de la social ( $60,8 \%$, frente al $60 \%$ de los mayores y al $48 \%$ de los jóvenes).

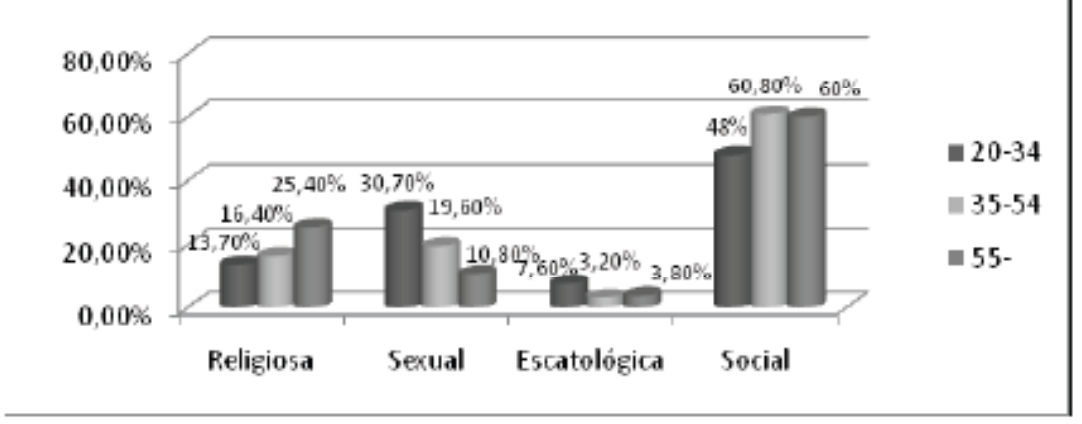

Gráfico 9. Esferas: edad

El nivel de instrucción y la clase social son factores relacionados que inciden, sin lugar a dudas, en el rendimiento funcional de las expresiones que aluden a conceptos o realidades interdictos en el habla semiformal de Madrid. En general, las personas con estudios primarios son las que más han producido formas del tipo de las que nos ocupan (546 casos, frente a 460 que han producido las personas con estudios medios y 472 que han producido los sujetos con estudios superiores). No obstante, las expresiones utilizadas por los sujetos con nivel de instrucción primario son, en su mayoría, neutras e indirectas (así es en el 89,4\% de los casos), como también ocurre, y en mayor proporción aún, en el discurso de las personas con instrucción media $(91,7 \%)$, frente al habla semiformal de los sujetos con estudios superiores, que presenta un $14,6 \%$ de producción de expresiones directas no neutras.

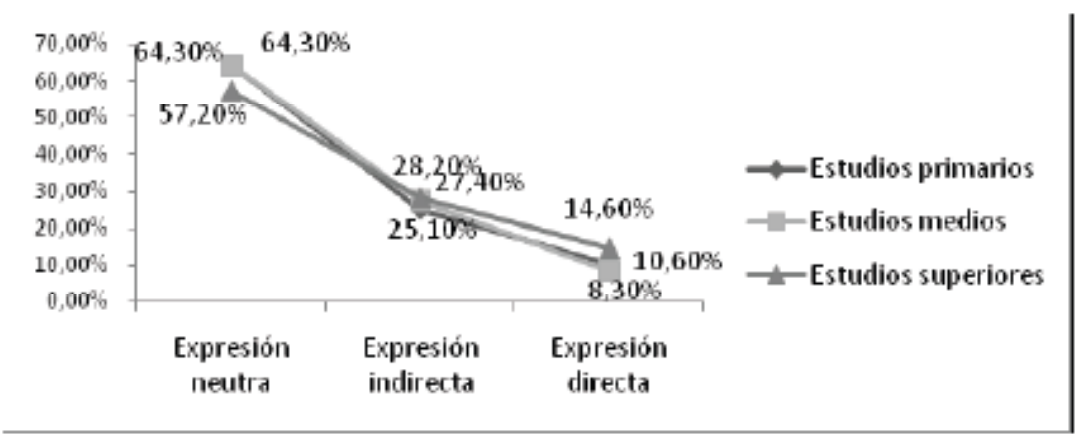

Gráfico 10. La expresión del tabú: nivel de instrucción 
Los datos asociados a la clase social permiten perfilar estos resultados, especialmente a partir del barrio de residencia ${ }^{32}$. Así, los hablantes del distrito de Vallecas han empleado considerablemente más expresiones de las que nos ocupan que los del distrito de Salamanca ( 828 frente a 650 ), lo que relaciona las clases sociales medias, medias-bajas y bajas con un mayor empleo de expresiones que aluden a entidades tabú. Además, la proporción en que se usan expresiones directas no neutras en la zona vallecana es mayor que la del barrio de Salamanca (12,4\% frente a 9,8\%), de la misma manera como ocurre con la proporción en la que utilizan los disfemismos las personas de clase media-baja (19\%, frente al 7,9\% de las personas de clase alta, al 7,8\% de las personas de clase baja y al 7,4\% de las personas de clase media).

En relación con la expresión neutra, directa o indirecta está la finalidad con la que usan los sujetos con diferente nivel de instrucción expresiones que aluden a conceptos o realidades interdictas. Es reseñable, especialmente, el hecho de que los informantes con un nivel de instrucción bajo o medio sean los que, en proporción, más empleen con finalidad informativa las unidades que nos ocupan, a diferencia de lo que ocurre con los sujetos de nivel alto, que destacan por un mayor uso de la finalidad encubridora y enfatizadora.

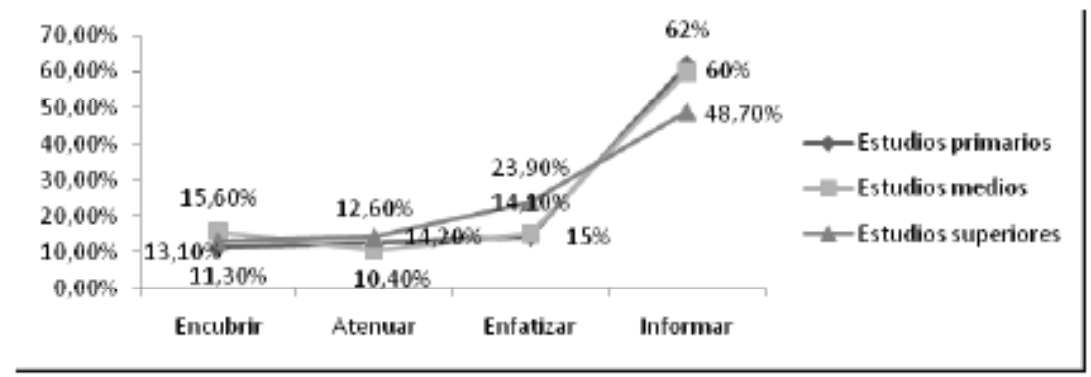

Gráfico 11. Finalidad de la expresión del tabú: nivel de instrucción

En Vallecas se utilizan las expresiones que aluden o han aludido a conceptos o realidades tabú, en proporción, más para informar (59,5\% frente al 53,2\% del barrio de Salamanca) y encubrir (16,2\%, frente al 9,5\%); mientras que, en

32 En el corpus PRESEEA-Madrid, la clase social es un factor de posestratificación y, por tanto, no podemos dar datos numéricos que sean significativamente comparables, ya que no contamos con el mismo número de informantes de cada clase establecida. Ofrecemos, por ello proporciones, que informan sobre tendencias interesantes. Por otro lado, el barrio de residencia (distritito de Salamanca o distrito de Vallecas) se asocia a clase social de forma directa $\mathrm{y}$, en este caso, si contamos con un número igual de informantes de cada barrio. 
el barrio de Salamanca, se da una mayor proporción de empleo de nuestras expresiones para atenuar $(17,2 \%$, frente al $8,7 \%$ del barrio de Vallecas) y enfatizar $(20 \%$, frente al $15,6 \%)$, en consonancia con lo que acontece con el uso que hacen de ellas personas de diferentes clases sociales: las entrevistas de personas de clases sociales bajas muestran las mayores proporciones de aparición de expresiones con finalidad de encubrir (el 18,9\% de sus expresiones, frente al $14,8 \%$ de las medias-bajas, al 11,6\% de las medias y al 7,9\% de las medias-altas) e informar (el 63,6\%, frente al 51,6\%, al 59,8\% y al $52,6 \%$ ), mientras que las de sujetos de clases sociales altas presentan un uso más destacado de estas expresiones para atenuar (el 17,6\%, frente al $5,9 \%$ de las clases bajas, al $11,8 \%$ de las medias bajas y al $13,7 \%$ de las medias) y enfatizar (el 21\%, frente al 18,1, el 21,8 y el 14,8).

Por último, consideramos conveniente mencionar que los sujetos con estudios superiores presentan, en su discurso semiformal, un uso mayor de expresiones pertenecientes a la esfera social $(60,2 \%$ de sus expresiones) y a la sexual $(20,8 \%)$, mientras que los que tienen estudios medios utilizan, en proporción, más expresiones de la esfera mágico-religiosa que el resto (21,5\% de sus expresiones) y los que tienen estudios primarios, de expresiones de la esfera escatológica $(6 \%)$.

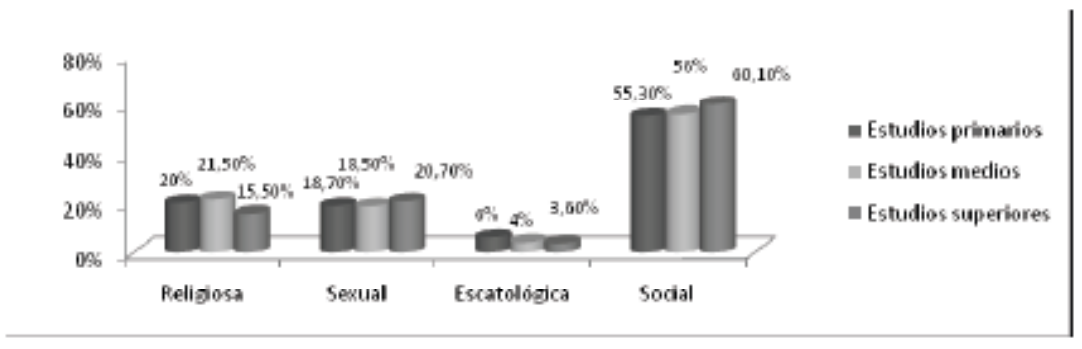

Gráfico 12. Esferas: nivel de instrucción

Los barrios y las clases sociales asociadas habitualmente a ellos permiten perfilar, de nuevo, estos datos, ya que hemos constatado que, proporcionalmente, los vallecanos emplean más expresiones de la esfera sexual que los sujetos del barrio de Salamanca (el 23,4\% de sus expresiones, frente al 14\%); estos últimos destacan, sin embargo, por un mayor uso de expresiones de la esfera religiosa (el $21,2 \%$ de sus expresiones, frente al 17,3 de los sujetos de Vallecas). En relación con la clase social, finalmente, es reseñable el hecho de que las mayores proporciones de expresiones pertenecientes a la esfera sexual sean producidas por sujetos de clases baja y media-baja (el $26 \%$ y el $25 \%$, respectivamente, de los totales de cada grupo), mientras que la clase media-alta y la alta son las que presentan 
mayor proporción de expresiones de las esferas social (el 63,3\% y el 63\%, respectivamente) y mágico-religiosa (el $19 \%$ y el $29 \%$, respectivamente). Los datos relacionan, pues, los mayores niveles de instrucción y las clases sociales más altas con menor uso de expresiones que aluden o han aludido a conceptos o realidades tabú y con las expresiones propias de las esferas sociales y religiosas, sobre las que la interdicción parece ser menor en la actualidad, y los niveles medios y bajos y las clases medias y bajas con el mayor uso de expresiones interdictas y con un mayor empleo, en proporción, de expresiones de la esfera sexual y escatológica ${ }^{33}$.

\section{CONCLUSIONES}

En las páginas precedentes hemos ofrecido datos relevantes acerca del uso que hacen los madrileños de expresiones lingüísticas que aluden a conceptos o realidades tabú, en discurso oral, producido en un registro medio de lengua. La situación comunicativa explica el uso mayoritario de expresiones neutras o indirectas, pertenecientes a las esferas social, religiosa o sexual, y empleadas con el fin básicamente de informar. En cualquier caso, los resultados obtenidos en los análisis realizados nos permiten constatar la pervivencia del tabú lingüístico en el siglo XXI, si bien en grados muy diferentes en las distintas esferas y áreas conceptuales, así como la finalidad pragmática y los factores sociales que se relacionan habitualmente con su empleo.

El estudio de la incidencia de las características sociales de los hablantes, específicamente el sexo, la edad, el nivel de instrucción y la zona de residencia (asociada a clases medias y bajas -distrito de Vallecas-o medias y altas -distrito de Salamanca-) ha revelado datos de gran interés que indican la existencia de patrones sociopragmáticos en el uso y la pervivencia de expresiones que aluden o han aludido a conceptos o realidades tabú. Como ya se había constatado en los estudios sociolingüísticos previos, las mujeres, habitualmente con un discurso con mayor riqueza léxica, utilizan más expresiones interdictas que los hombres, pero eligiendo, mayoritariamente, formas neutras o procedimientos indirectos; los hombres, por su parte, en

33 El análisis del factor modo de vida, posestratificacional también, no ha arrojado datos interesantes. 
proporción, utilizan más expresiones directas, marcadas, que las mujeres. En la interacción semiformal de las madrileñas, las expresiones que nos ocupan se usan más para informar y encubrir que en la de los madrileños, mientras que los hombres enfatizan y atenúan con ellas más que la mujer. Además, la mujer hace más uso de expresiones pertenecientes a la esfera religiosa y social que el hombre, las menos tabuizadas, y el hombre utiliza más asiduamente expresiones de la esfera sexual y escatológica que la mujer.

En Madrid, los mayores y los adultos hacen un empleo mucho más destacado de expresiones que hacen referencia a conceptos o realidades interdictas que los jóvenes. No obstante, como se ha revelado en otros estudios de corte sociolingüístico, los jóvenes madrileños, proporcionalmente, son los que más las emplean de manera marcada, ya sea indirecta o directamente, especialmente para enfatizar. Por otro lado, los jóvenes emplean en su discurso semiformal más expresiones sexuales y escatológicas que los adultos y que los mayores; estos últimos utilizan en mayor proporción las pertenecientes a la esfera social que los miembros de los otros grupos, y los mayores, por su parte, utilizan más las propias de la esfera mágico-religiosa que el resto de informantes. Podemos decir, pues, que el poder y la seguridad que confiere la edad favorece o no limita tanto, la expresión del tabú, si bien depende del grado de interdicción de las esferas y de los conceptos interdictos a los que se alude.

Por último, el nivel de instrucción de los sujetos se ha mostrado, también, como factor significativo: utilizan más expresiones para hacer referencia a conceptos o realidades tabú las personas con instrucción primaria, que las que tienen un grado medio o alto de instrucción, si bien hacen un uso más asiduo, proporcionalmente, de unidades lingüísticas neutras o indirectas. Además, junto con los informantes de nivel medio, son los que más las emplean con finalidad informativa, mientras que los sujetos con educación superior hacen un uso destacado de nuestras expresiones con finalidad encubridora y enfatizadora. Por otra parte, los madrileños con estudios primarios son los que, en proporción, más emplean expresiones de la esfera escatológica, en contrapartida a los que tienen estudios medios, que son los que más utilizan expresiones de la esfera mágico-religiosa, y a los individuos con estudios superiores, que son los que hacen un mayor uso de expresiones de la esfera social y de la sexual. De nuevo, podemos ver que el poder y la seguridad que proporcionan los estudios y la clase social están en estrecha relación con la expresión directa, marcada y enfática, así como con el empleo de formas pertenecientes a esferas sobre las que pesan diferentes grados de interdicción.

Los datos que acabamos de ofrecer confirman muchos de los hallazgos de estudios sociolingüísticos previos sobre el tabú, pero, en esta ocasión, obtenidos a partir del análisis de lo que acontece en discurso oral, semiformal, 
y con respecto a esferas interdictas distintas de la sexual. Esperamos ofrecer en breve información más detallada sobre las formas de uso frecuente y la configuración de las esferas mismas y los resultados de la segunda parte de la investigación, en la que estamos atendiendo a qué percepción muestran los madrileños del empleo que hacen de expresiones tabú a partir del estudio de los resultados de cuestionarios, aplicados a sujetos madrileños de los distritos de Vallecas y Salamanca, diseñados teniendo en cuenta los empleados en diversos estudios sociolingüísticos y recogidos para tal fin.

\section{REFERENCIAS BIBLIOGRÁFICAS}

Allan, Keith y Kate Burridge. 1991. Euphemism and Dysphemism. Language Used as Shield and Weapon. Nueva York, Oxford: Oxford University Press.

2006. Forbidden words. Nueva York: Cambridge University Press.

Briz Gómez, ANTonio. 1996. Los intensificadores en la conversación coloquial. En Antonio Briz Gómez, José Ramón Gómez Molina, M. José Martínez Alcalde y Grupo Val.Es.Co (eds.). Pragmática y gramática del español hablado. Actas del II Simposio sobre Análisis del Discurso Oral, pp. 13-36. Valencia: Libros Pórtico. Ariel.

1998. El español coloquial en la conversación. Esbozo de pragmática. Barcelona:

CAlvo Shadid, AnNette. 2008. Análisis sociolingüistico sobre el tabú sexual en el español de Costa Rica. Tesis para optar al grado de Doctora, Universidad de Bergen.

2011. Sobre el tabú, el tabú lingüístico y su estado de la cuestión. Kañina, Revista Artes y Letras, Universidad de Costa Rica XXXV (2): 121-145. Disponible en http:// revistas.ucr.ac.cr/index.php/kanina/article/viewFile/558/617

(2013). El tabú sexual en el español de Costa Rica: análisis sociolingüístico. Kañina, Revista Artes y Letras, Universidad de Costa Rica XXXVII (1): 177-201. Disponible en http://163.178.114.46/latindex/index.php/kanina/article/view/10582

Casas Gómez, Miguel. 1986. La interdicción lingüistica. Mecanismos del eufemismo y Disfemismo. Cádiz: Servicio de publicaciones de la Universidad de Cádiz.

1993. A propósito del concepto lingüístico de eufemismo como sincretismo léxico: su relación con la sinonimia y la homonimia. Iberoromania 37: 70-90.

2000. Tabú de palabra e interdicción conceptual. En Antonio Pamies Bertrán y Juan de Dios Luque Durán (eds.). Trabajos de lexicografia y fraseología contrastivas, pp. 79-98. Granada: Método Ediciones.

2005. Precisiones conceptuales en el ámbito de la interdicción lingüística. En Luis Santos Ríos (ed.). Palabras, norma, discurso: en memoria de Fernando Lázaro Carreter, pp. 271-290. Salamanca: Ediciones Universidad de Salamanca.

2009a. Hacia una nueva perspectiva de enfoque en la definición lingüística del eufemismo. En Catalina Fuentes Rodríguez y Esperanza R. Alcaide Lara (eds.). Manifestaciones textuales de la descortesía y agresividad verbal en diversos ámbitos comunicativos, pp. 11-29. Málaga: Universidad de Andalucía. 
2009b. Towards a New Approach to the Linguistic Definition of Euphemism. Language Sciences 6 (31): 725-739.

2012a. De una visión léxica y pragmático-discursiva a una dimensión cognitiva en la caracterización extralingüística y lingüística del eufemismo. En Marc Bonhomme, Mariela de la Torre y André Horak (eds.). Études pragmático-discursives sur l'euphémisme, pp. 53-72. Frankfurt am Main: Peter Lang.

2012b. El realce expresivo como función eufemística: a propósito de la corrección política de ciertos usos lingüísticos. En Ursula Reutner y Elmar Schafroth (eds.). Political Correctness, pp. 61-77. Frankfurt am Main: Peter Lang.

Cestero Mancera, Ana M. 2012. El proyecto para el estudio sociolingüístico del español de España y América (PRESEEA). Español Actual 98: 227-234.

2015. Estudio sociolingüístico del tabú en el habla de Madrid: propuesta metodológica y primeros resultados. En Ana M. Cestero Mancera, Isabel Molina Martos y Florentino Paredes García (eds.). Patrones sociolingüísticos de Madrid, 287-348. Frankfurt am Main: Peter Lang.

Cestero Mancera, Ana M., Isabel Molina Martos y Florentino Paredes García. 2012. La lengua hablada en Madrid. Corpus PRESEEA-Madrid (distrito de Salamanca), Volumen I. Hablantes de Instrucción Superior. Alcalá de Henares: Universidad de Alcalá, Servicio de Publicaciones.

2015. El estudio sociolingüístico de Madrid. En Ana M. Cestero Mancera, Isabel Molina Martos y Florentino Paredes García (eds.). Patrones sociolingüísticos de Madrid, pp. 17-62. Frankfurt am Main: Peter Lang.

Chamizo Domínguez, Pedro J. 2003. La función social y cognitiva del eufemismo y del disfemismo.Panace@V(15): 45-51. Disponible en http://es.scribd.com/doc/170483813/ La-funcion-social-y-cognitiva-del-eufemismo-Pedro-Chamizo-Dominguez\#scribd

2008. Tabú y lenguaje: las palabras vitandas y la censura lingüística. Themata. Revista de Filosofia 40: 31-46. Disponible en http://institucional.us.es/revistas/themata/40/ Chamizo.pdf

2009. Linguistic interdiction: Its status quaestionis and possible future research lines. Language Sciences 31(4): 428-446.

Chamizo Domínguez, Pedro J. y Francisco Sánchez Benedito. 2000. Lo que nunca se aprendió en clase. Eufemismos y disfemismos en el lenguaje erótico inglés. Granada: Comares.

Crespo Fernández, Eliecer. 2007. El eufemismo y el disfemismo. Procesos de manipulación del tabú en el lenguaje literario inglés. Alicante: Publicaciones Universidad de Alicante.

2008. Sex-related Euphemism and Dysphemism: Ananalysis in Terms of Conceptual Metaphor. Atlantis. Journal of the Spanish Association of Anglo-American Studies 2(30): 95-110. Disponible en http://dialnet.unirioja.es/servlet/articulo?codigo=3269290

Danbolt Drange, Eli-Marie. 1997. La mujer y el tabú. Un análisis sociolingüístico del tabú en el lenguaje femenino de Viña del Mar. Tesis para optar al grado de Máster, Universidad de Bergen.

Díaz Pérez, Juan Carlos. 2012. Pragmalingüística del disfemismo y la descortesía. Tesis para optar al grado de Doctor, Universidad Carlos III de Madrid. Disponible en http://earchivo.uc3m.es/bitstream/handle/10016/15682/Tesis_Doctoral_Juan_Carlos_Diaz_ Perez_UC3M_2012.pdf?sequence $=1$

Fernández de Molina Ortés, Elena. 2014. La presencia de eufemismos y disfemismos en el campo semántico del cuerpo humano. Estudio sociolingüístico. Pragmalingüística 22: 8-30.

García Platero, Juan Manuel. 2010. Usos afijales descorteses en registros formales. Discurso y Sociedad 4 (4): 809-827. Disponible en http://www.dissoc.org/ediciones/v04n04/DS4(4) Garcia.pdf 
Grimes, LARRY M. 1978. El tabú lingüistico en México: el lenguaje erótico de los mexicanos. New York: Bilingual Review Press.

Hare, Cecilia. 1995. Algunos eufemismos peruanos desde un punto de vista socio-lingüístico. En Actas del IV Congreso Internacional de El español de América, I, pp. 336-340. Santiago de Chile: Pontificia Universidad Católica de Chile, Instituto de Letras.

Kany, Charles E. 1960. American-Spanish Euphemism. Berkeley and Los Angeles: University of California Press.

López Morales, Humberto. 1990. Sociolingüistica del tabú. El caso de Puerto Rico. Madrid: MS.

1997. Papel del nivel sociocultural y del estilo lingüístico en el uso del eufemismo. En Francisco Moreno Fernández (ed.). Trabajos de sociolingüistica hispánica, pp. 27-33. Alcalá de Henares: Servicio de Publicaciones de la UAH.

2001. Estratificación social del tabú lingüístico: el caso de Puerto Rico. Estudios de lingüistica del español 13. Disponible en http://elies.rediris.es/elies13/index.htm\#indice 2005. Sociolingüística del tabú. Interlingüistica 16 (1): 7-20. Disponible en http:// dialnet.unirioja.es/servlet/articulo?codigo $=2514205$

Martínez Valdueza, María del Pilar. 1995. El tabú lingüístico: estudio sociolingüistico de Las Palmas de Gran Canaria. Tesis para optar al grado de Doctora, Universidad de Las Palmas de Gran Canaria.

1998. Status quaestionis: el tabú lingüístico. Lingüistica 10: 115-139.

Molina Martos, Isabel, Florentino Paredes García y Ana M. Cestero. 2014. La lengua hablada en Madrid. Corpus PRESEEA-Madrid (distrito de Salamanca), Volumen II. Hablantes de Instrucción Media. Alcalá de Henares: Universidad de Alcalá, Servicio de Publicaciones.

Montero Cartelle, Emilio. 1981. El eufemismo en Galicia (Su comparación con otras áreas romances). Verba: Anuario Galego de Filología (Anexo 17). Santiago de Compostela.

1995. La interdicción sexual en el gallego medieval: la expresión de los órganos sexuales femeninos. Verba: Anuario galego de filoloxia (22): 429-447.

2000. El tabú, el eufemismo y las hablas jergales. En Manuel Alvar (dir.). Introducción a la Lingüística española, pp. 547-563. Madrid: Ariel.

Moreno Fernández, Francisco. 1996. Metodología del 'Proyecto para el estudio sociolingüístico del Español de España y de América' (PRESEEA). Lingüística 8: 257-287.

2005. Corpus para el estudio del español en su variación geográfica y social. El corpus 'PRESEEA'. Oralia 8: 123-139.

2006. Información básica sobre el "Proyecto para el Estudio Sociolingüístico del Español de España y de América - PRESEEA (1996-2010)". Revista Española de Lingüística 36: 385-391.

2012. Sociolingüistica cognitiva. Proposiciones, escolios y Debates. Madrid/ Frankfurt: Iberoamericana/Vervuert.

Moreno Fernández, Francisco, Ana M. Cestero Mancera, Isabel Molina Martos y Florentino Paredes García. 2000. La sociolingüística de Alcalá de Henares en el "Proyecto para el Estudio Sociolingüístico del Español de España y América" (PRESEEA). Oralia 3: 149-168.

NAVDal, ToRe. 2007. Las palabras tabú del lenguaje juvenil madrileño. Tesis para optar al grado de Máster, Universidad de Bergen. Disponible en https://bora.uib.no/bitstream/ handle/1956/2612/Masterthesis_Navdal.pdf?sequence $=1$

Paredes García, Florentino, Ana M. Cestero Mancera e Isabel Molina Martos. 2015. La lengua hablada en Madrid. Corpus PRESEEA-Madrid (distrito de Salamanca), Volumen 
III. Hablantes de Instrucción Baja. Alcalá de Henares: Universidad de Alcalá, Servicio de Publicaciones.

Pizarro Pedraza, Andrea. 2013. Tabú y eufemismo en la ciudad de Madrid. Estudio sociolingüístico-cognitivo de los conceptos sexuales. Tesis para optar al grado de Doctora, Universidad Complutense de Madrid. Disponible en http://eprints.ucm.es/24937/1/ T35255.pdf

PRESEEA. 2003. Metodología del 'Proyecto para el estudio sociolingüístico del español de España y de América PRESEEA'. Disponible en http://preseea.linguas.net/

Uría VARela, JAVIER. 1997. Tabú y eufemismo en latín. Ámsterdam: A. M. Hakkert.

Vestad, GuRi. 1991. Análisis sociolingüistico del vocabulario malsonante castellano. Tesis para optar al grado de Máster, Universidad de Oslo. 